\title{
Spatio-temporal variability and predictability of summer monsoon onset over the Philippines
}

\author{
V. Moron $\left({ }^{\circ},{ }^{\circ}, \&,+\right)^{1}$, A. Lucero $(*)$, F. Hilario (*), B. Lyon (+), A.W. Robertson $(+)$, \\ D. DeWitt $(+)$
}

○UFR des Sciences Géographiques et de l'Aménagement, Université d'Aix-Marseille I, Aix en Provence, France ${ }^{\circ}$ CEREGE, UMR 6635 CNRS, Aix en Provence, France \& Institut Universitaire de France, Paris, France

+ International Research Institute for Climate and Society, Columbia University, USA

* Philippine Atmospheric Geophysical and Astronomical Services Administration, Manila, Philippines

Submitted to Climate Dynamics

Revised version

November 2008

${ }^{1}$ Corresponding author address : Pr. Vincent Moron, CEREGE, UMR 6635, Europôle Méditerranéen de l'Arbois, BP 80, Aix en Provence, F-13545 (email : moron@cerege.fr) 


\begin{abstract}
The spatio-temporal variability of boreal summer monsoon onset over the Philippines is studied through the analysis of daily rainfall data across a network of 76 gauges for the period 1977 to 2004 and the pentad Merged Analysis of Precipitation from the US Climate Prediction Center from 1979 to 2006 . The onset date is defined using a local agronomic definition, namely the first wet day of a 5-day period receiving at least $40 \mathrm{~mm}$ without any 15 -day dry spell receiving less than $5 \mathrm{~mm}$ in the 30 days following the start of that period. The onset is found to occur rather abruptly across the western Philippines around mid-May on average and is associated with the set-up of a "classical" monsoonal circulation with low-level easterlies subsequently veering to southerly, and then southwesterly. The onset manifests itself merely as a seasonal increase of rainfall over the eastern Philippines, where rainfall occurs throughout most of the year.
\end{abstract}

Interannual variability of the onset date is shown to consist of a spatially coherent large-scale component, rather similar over the western and eastern Philippines, with a moderate to high amount of local-scale (i.e. station scale) noise. In consequence, the large-scale signal can be easily retrieved from any sample of at least 5-6 stations across the network although the localscale coherence and fingerprint of the large-scale signal of the onset date are found to be stronger over the central Philippines, roughly from Southern Luzon to Northern Mindanao. The seasonal predictability of local onset is analyzed through a cross-validated canonical correlation analysis using tropical Pacific and Indian Ocean sea surface temperature in March and the $850 \mathrm{hPa}$ May wind field from dynamical forecast models as predictors. The regional-scale onset, defined as the average of standardized local-scale anomalies in onset date, shows good predictive skill $(\mathrm{r} \approx 0.8)$. Moreover, most of the stations show weak to moderate skill (median skill $=0.28-0.43$ depending on the scheme) with spatial averaging across stations typically increasing skill to $>0.6$. 


\section{Introduction}

Seasonal forecasts of tropical rainfall are typically issued in (probabilistic) terms of three-month average rainfall amount (e.g. Goddard et al. 2001) since the convective nature of tropical rainfall makes it highly variable, and therefore less predictable, on shorter timescales. Seasonal averaging serves to reduce the "noise" associated with daily rainfall allowing the influence of more persistent, large-scale climatic perturbations such as the El Niño Southern Oscillation (ENSO) to be expressed. While the large-scale picture of ENSO-related, seasonal rainfall teleconnections has been documented (e.g., Ropelewski and Halpert 1987 1996; Kiladis and Diaz 1989; Yasunari 1991; Webster et al 1998), the influence of ENSO (or other phenomena) on local-scale rainfall on sub-seasonal time scales remains to be fully explored. For example, an anomalously dry (wet) season could be associated with fewer (more) rainy days, and/or lower (higher) amounts of rainfall during wet days, and/or a delayed (early) onset or early (delayed) withdrawal of the rainy season.

In this paper, we consider the spatial coherence and seasonal predictability of the onset of the boreal summer monsoon across the Philippines. The date of onset of the summer rainy season is of particular importance to the agriculture sector in the Philippines and information on its early or late arrival is frequently sought from the climate services branch of the Philippine Atmospheric, Geophysical and Astronomical Services Administration (PAGASA). Among the larger users of this information are the agriculture, transportation, construction, and electric service sectors. Others, like water managers and conservationists also formulate plans based on climate outlooks to help optimize the use of water. PAGASA is actively working on improvements to its prediction methods including the prediction of the onset of the summer rainy season to meet these various sectoral needs. 
Most previous studies of the monsoon onset have used a more-or-less smoothed annual cycle of gridded $\left(2.5^{\circ}\right.$ by $\left.2.5^{\circ}\right)$ outgoing longwave radiation (OLR; e.g. Wu and Wang 2000; Mao et al 2004) or U.S. Climate Prediction Center (CPC) Merged Analysis of Precipitation (CMAP; Xie and Arkin 1997 1998) data (e.g. Murakami and Matsumoto 1994; Wang 1994; Wang and LinHo 2002). A few studies have considered spatially-averaged daily rainfall at the regional scale, such as over Indochina (Zhang et al 2004). At this scale, the monsoon onset is usually viewed as a multi-stage phenomena, progressing from the Indochina Peninsula and South China Sea (SCS) in early to mid-May, eastward to the Philippines Sea (mid June) and lastly, to the central northern Tropical Pacific Ocean (mid July) (e.g. Wu and Zhang 1998; Wu and Wang 2000 2001; Wang and LinHo 2002; Ding 2004). The interannual variability of large-scale monsoon onset is strongly associated with ENSO, with warm (cold) ENSO events in the preceding spring related to late (early) onset (Wu and Wang 2000; Zhang et al. 2002). However, the relationships between monsoon onset timing across the Philippines and ENSO have not previously been analyzed.

The current study focuses specifically on the Philippines and utilizes observations from a network of 76 stations across the country. We define onset according to a local agronomical definition appropriate to end-user needs, especially in the agriculture sector (Sivakumar 1988; Marteau et al 2008; Moron et al 2008). As will be shown, the interannual variability in timing of onset by this definition relates to clearly defined features in the regional atmospheric circulation and sea surface temperatures (SST). The main goal of this paper is to examine in detail the monsoon onset over the Philippines at the station scale, together with its relationship with the large-scale monsoon circulation. The seasonal predictability of onset (i.e. predictions of onset made at 
greater than 1 month lead time) will be assessed through the use of canonical correlation analysis (CCA) and general circulation model (GCM) retrospective forecasts.

The paper proceeds as follows. The study region is described in section 2. Data sets used and seasonal forecast models are described in section 3. The climatology and interannual variability of the onset date is then analyzed (section 4) and the sensitivity of onset date to spatial sampling is carefully studied (section 5). The predictability of onset date is first estimated empirically through a cross-validated CCA using March SST as predictors, and secondly from retrospective GCM forecasts of monthly mean winds in May from 3 sets of numerical experiments initialized on April $1^{\text {st }}$ (section 6). A summary and discussion concludes the paper (section 7).

\section{The study region}

The Philippines archipelago numbers more than 7000 islands of various sizes with the relatively large islands of Luzon in the north and Mindanao to the south and the cluster of Visayan Islands between them (Fig. 1). Geologically, the Philippines are part of the western Pacific arc system, with numerous active volcanoes and a complex orography, with mountain ranges usually oriented parallel to the main axis of the Islands. The highest summit is Mount Apo (2978 m) in Mindanao. The eastern islands are usually lower in elevation than Luzon, Mindanao and the western ones. Most of the Philippines Archipelago belongs to the western North Pacific (WNP) boreal summer monsoon region, itself included in the broad-scale Asian-Pacific southwest monsoon system (e.g. Murakami and Matsumoto 1994; Wang 1994; Webster et al 1998; Wang et al 2001; Wang and LinHo 2002). The influence of the southwest monsoon is most pronounced over the western Philippines (Akasaka et al 2007; Moron et al 2007a), while rainfall in the eastern part of the 
country is also significantly influenced by the interaction of low-level easterlies and the orography during boreal autumn and winter.

The tropical marine climate of the Philippines is divided into four climate types by PAGASA, also known as the Modified Coronas Classification (Fig. 1). This classification was first established by Coronas (1920) and then slightly modified by PAGASA (Flores et al 1969; Kintanar 1984). Most of the western Philippines, north of Negros, facing the SCS has a distinct summer monsoonal rainfall regime (PAGASA "Type I" climate) with an almost completely dry season from November to April and a pronounced wet season from May to October when monthly rainfall typically ranges between 300 and $500 \mathrm{~mm}$. By contrast, the eastern Philippines, facing the Philippines Sea, has no real dry season with a seasonal peak of rainfall in NovemberDecember (Type II). The intermediate band (Type III) is somewhat similar to Type I, with a rather clear maximum of rainfall from May to October, but also shares aspects of Type II (i.e. rain also occurs during boreal autumn and winter). Type IV is located in the south and has rainfall more or less evenly distributed throughout the year. The impact of orography on the climate types is striking, for example over Northern Luzon (Fig. 1), where a group of 4 Type III stations are located over the central plain of Cagayan Valley, while Type I stations face the SCS west of the Cordillera mountain ranges and Type II stations face the Philippines Sea east of Sierra Madre mountains.

Interannual variability of rainfall over most areas is dominated by ENSO, with unusually dry (wet) conditions experienced in warm (cold) ENSO years during most of the calendar year (e.g., Jose and Cruz 1999). However, recent studies (Lyon et al 2006; Lyon and Camargo 2008) showed that the seasonal rainfall response to ENSO reverses sign between boreal summer (July - 
September) and fall (October - December) during both ENSO phases. During boreal spring, warm (cold) ENSO events are associated with anomalous upper-level confluence (diffluence) over the WNP and a delay (advance) in the northeastward shift of the North Pacific subtropical anticyclone (Wu and Wang 2000; Wang et al 2000; Wang and Zhang 2002; Mao et al 2004).

\section{Data}

\section{a. Rainfall station data}

The analysis of station rainfall is based on a 76-station network of daily rainfall records from 1979-2004 compiled and quality controlled by PAGASA. Daily rainfall amounts of less than 1 $\mathrm{mm}$ were set to zero before the analysis to reduce possible biases associated with very small rainfall amounts (Moron et al 2007b). Missing entries (<3\%) were typically scattered in space and time, although one station (San José, Mindoro) had four contiguous missing years (19771980). Missing data were filled using a simple stochastic weather generator (SWG) applied at each station individually, with parameters estimated for each calendar month separately (Wilks 1999). The sequence of dry and wet days is simulated using the Markov chain principle, with the dry-to-dry and wet-to-dry persistence computed from the available data. Rainfall amounts of wet days $>1 \mathrm{~mm}$ are sampled stochastically from a gamma distribution with shape and scale parameters computed from the available wet days.

\section{b. Gridded precipitation data}

Pentad rainfall estimates were extracted from the 2.5-degree gridded CMAP dataset, which is based on a combination of gauge observations and satellite estimates (Xie and Arkin 1997 1998). These data were selected over a regional window centred on the Philippines $\left(100^{\circ}-135^{\circ} \mathrm{E}, 0^{\circ}-\right.$ $25^{\circ} \mathrm{N}$ ), from January 1979 to December 2004; there are no missing entries during this period. 


\section{c. Reanalysis wind data}

The zonal and meridional components of 2.5-degree gridded daily winds from the NCEP-NCAR Reanalysis (Kalnay et al 1996) at 850 and $200 \mathrm{hPa}$ were selected over a regional window centred on the Philippines $\left(100^{\circ}-140^{\circ} \mathrm{E}, 0^{\circ}-30^{\circ} \mathrm{N}\right)$ from January 1977 to December 2004.

\section{d. Seasonal climate forecast models}

Three sets of GCM retrospective seasonal forecasts are used to estimate the seasonal predictability of onset date. The first set comes from the ECHAM4.5/constructed analogue SST (ECHAM-CA hereafter) two-tier system (Li et al 2008) and consists of 24 ensemble members initialized on April $1^{\text {st }}$ of each year 1977 to 2004. In this two-tier system, monthly SST is first predicted from the previous month (here March) using the constructed analogue method (van den Dool 1994). The ECHAM 4.5 is then run at T42 horizontal resolution using the monthly SST predictions interpolated linearly to daily values at the lower boundary with the 24 ensemble members initialized on April $1^{\text {st }}$ from slightly differing initial atmospheric conditions. The second and third sets of forecasts come from two coupled ocean-atmosphere GCMs, ECHAM4.5-MOM3 (hereafter ECHAM-MOM; DeWitt 2005) with 9 ensemble members from 1977 to 2001, and the NCEP Climate Forecast System (CFS) with 15 ensemble members from 1981 to 2001 (Saha et al 2006); both sets are initialized on April $1^{\text {st }}$. The zonal and meridional components of the wind at $850 \mathrm{hPa}$ were selected over the $110^{\circ}-135^{\circ} \mathrm{E}$ and $0^{\circ}-25^{\circ} \mathrm{N}$ domain in each case.

\section{Climatological distribution of monsoon onset \\ a. Seasonal cycle of daily rainfall}


Figure 2 shows a classification of the 76 stations into 2 groups according to their mean seasonal cycle of rainfall frequency, made using the k-means method (Diday and Simon 1976). The mean seasonal cycle at each station is computed from the daily rainfall frequency for each calendar day, averaged across the 28 years of the dataset, and then low-pass filtered to remove variations with periods $<120$ days. The filtered seasonal cycles for each station were then standardized to have zero mean and unit variance and clustered using a k-means algorithm. The west-east division of the Philippines into two clusters matches closely with PAGASA's climate classification (Fig. 1) with almost all western (eastern) stations in climate Types I and III (II and IV). The western Philippines has a clear summer monsoonal rainfall regime with low rainfall ( $<<$ $5 \mathrm{~mm} /$ day) from late- November to April and peak rainfall from mid-June to mid-September. The mean onset takes place quite abruptly around mid-May. The seasonal cycle is less clearly defined for the eastern Philippines because there is no absolute dry season. Rainfall peaks there from November to January but there is also a relative maximum in July and an increase of rainfall amount is also seen from April to June-July as for the western Philippines. There is a second relative minimum in August (Fig. 2c).

\section{b. Onset dates}

Onset dates computed from the station network and CMAP datasets are plotted in Fig. 3, in terms of the median and the $25^{\text {th }}$ and $75^{\text {th }}$ percentiles of the distribution across years. The monsoon onset date is defined for both datasets to be the first wet day of a 5-day period receiving at least $40 \mathrm{~mm}$ without any 15-day dry spell receiving less than $5 \mathrm{~mm}$ in the 30 days following the start of that period. The second criterion helps to avoid onset dates that represent "false" starts. The computation starts from the first of April, which is the driest month of the year climatologically (averaged across all locations). In a few cases (2.7\%) using the station data, the onset is not 
defined (for example for a very dry year/station); 61 stations have a defined onset each year and 10 stations have just one undefined onset. A single station (Tagbilaran $123.9^{\circ} \mathrm{E}, 9.6^{\circ} \mathrm{N}$ on Bohol Island) has 24 years with undefined onset, related to the dryness of this station. False starts (defined as a difference between the first wet 5-day sequence $>40 \mathrm{~mm}$ and the onset as defined above) were observed in $15 \%$ of cases, and are most frequent along the coast, especially for the interior low-lying islands (Cebu, Bohol, Leyte, etc.).

For the 76 stations, the median onset date across years varies between April 5 and June 26 depending on the station (Fig. 3f), and is very close to the mean. Median onset occurs more than 15 days earlier in the Type II climate in the east than in the Type I climate in the west (Table I). However, this apparent progression (not seen in the CMAP) could be an artefact of moderate rainfall already occurring in the east in April, allowing the onset criteria (based on absolute rainfall amounts) to be reached earlier in the east, especially over topography. Higher elevations tend to have earlier onset than surrounding lowlands, probably because orographic uplift enhances convection thus meeting the onset criteria sooner. For example, the median onset occurs 12 days earlier at Baguio $\left(120.6^{\circ} \mathrm{E}, 16.4^{\circ} \mathrm{N}\right.$, elevation $\left.1501 \mathrm{~m}\right)$ than at Dagupan $\left(120.3^{\circ} \mathrm{E}\right.$, $16.1^{\circ} \mathrm{N}$, elevation $1 \mathrm{~m}$ ), situated less than $50 \mathrm{~km}$ away on the western coast of Luzon. The latest onset dates are typically observed along the western coast and for the inner islands (Cebu, Bohol, Leyte, etc.) of the central Philippines, the latter having either relatively flat topography or being located in rain-shadowed locations. The inter-quartile range across years, given by the $25^{\text {th }}$ and $75^{\text {th }}$ percentiles (Figs. 3e,g), varies between 10-20 days for few stations spread over central and NW Luzon and Mindanao to 30-50 days over the central Philippines from southern Luzon to northern Mindanao. Note that the onset date is not really relevant for few easternmost stations which are wet almost all-year round (e.g. Hinatuan, $\left.8.37^{\circ} \mathrm{N}, 126.34^{\circ} \mathrm{E}\right)$. In that case, the onset 
date according to our definition always occurs during the first few days of April, simply because of the starting date of the computation.

Median onset dates from the CMAP dataset (Fig. 3b) show an overall northward progression from equatorial latitudes (mid to late April) toward $15^{\circ}-20^{\circ} \mathrm{N}$ (mid-May). The early onset hinted over southern China could be associated with the pre-Mei-Yu season, defined as the first quasistationary stage of the East Asian monsoon trough (Chang and Chen 1995; Wu and Zhang 1998; Wang et al 2000; Wu et al 2007), rather than the onset of the monsoon proper. However, the larger-scale northward progression in the CMAP appears to be weak over the Philippines, because the complex local-scale behaviour of the monsoon onset reflected in the station data tends to be smoothed by the CMAP $2.5^{\circ}$ grid resolution. Overall, our estimates of median onset date are close to previous estimates of mean onset date (e.g. Akasaka et al 2007). Wu and Wang (2000, 2001) and Wang and Linho (2002) found a mean onset date of pentads 27-29 (i.e. May 11-26) across the whole SCS and western Philippines, while Zhang et al (2004) found a slightly earlier mean onset date (May 9) over the central Indochina Peninsula. Early to mid-May also coincides with mean onset across the SCS, southern China and the Philippines in the studies of Chang and Chen (1995) and Lau and Yang (1997).

\section{c. Atmospheric circulation changes associated with mean onset}

Composites of reanalysis wind fields, CMAP precipitation and station rainfall are plotted in Fig. 4 for 10-day periods keyed to the onset date, with the latter averaged over the 76 stations on a yearly basis. The interannual standard deviation of this spatial average is 15 days, with the earliest station-average onset on April 20 (1999) and latest on June 14 (1983). Note that these 
analyses differ from those of Akasaka et al (2007), who considered long-term climatological averages when producing their composites.

The pre-onset circulation at low levels (days 20-11 and 10-1 before onset) consists of easterly flow across the Philippines (Fig. 4a,b) which then veers, gaining a southerly component over the SCS. These easterlies are associated with the southwestern flank of the extensive subtropical North Pacific anticyclone that exerts strong control over the Philippines prior to onset (Wu and Wang 2000 2001; Mao et al 2004; Akasaka et al 2007). At the station scale during the pre-onset (Fig. 4e,f), much of the western and central Philippines falls under a rain-shadow, while the easterly flow across the Philippines weakens progressively as onset approaches. We note that the mean onset date used here (averaged across all stations) blurs intra-Philippine variability with the onset of the rainy season already occurring at several stations a week or more before the average onset.

The 10-day period following the onset (Fig. 4c,g) is characterized by a further veering of the low level winds from easterlies to weak southerlies over SCS as the subtropical anticyclone recedes northeastward and convection develops over the SCS (Liu et al 2002). The mean winds are weak across the Philippines during this time, especially over the northern part of the country. Both rainfall datasets show a clear increase of precipitation over northwest Luzon and the adjacent SCS associated with weak southerlies, and likely an enhanced moisture flux. Rainfall is still relatively weak over the central Philippines (Fig. 4g). From day 11 to 20, the southerly flow strengthens considerably across the whole SCS while the flow remains weak over Mindanao (Fig. 4d); rainfall becomes largest on the western side of the Philippines at this time, due to the strong onshore southwesterlies (Fig. 4h). 
Wind field changes at $200 \mathrm{hPa}$ (not shown) are less dramatic and are governed by the northwestward migration of a centre of anticyclonic vorticity toward northern India. During May, the Philippines lie at the eastern fringe of this upper-level monsoon anticyclone, centred between northwest India and the WNP (Liu et al 2001). The flow is rather weak before the onset but strengthens markedly following it with a maximum along a longitudinal axis near $20^{\circ} \mathrm{N}$.

In summary, the onset of the summer monsoon over the Philippines can be understood as a regional-scale expression of larger-scale seasonal changes associated with the northeastward shift of the North Pacific subtropical anticyclone and development of SW flow across the SCS and the Philippines. This is consistent with the rapid onset across the whole Philippines at the station scale, subject to local-scale topographic influences, and despite the fact that onset is less clear over the eastern Philippines which is exposed to pre-onset moist easterly flow.

\section{Interannual variability of monsoon onset}

a. Variability in onset date

Considering that an undefined onset is defined by the absence of a 5-day wet spell $>40 \mathrm{~mm}$ not followed by a 15 -day dry spell $<5 \mathrm{~mm}$, the undefined onset dates in both datasets are replaced by the latest onset date available for each year. Interannual variability of onset date is depicted in Fig. 5 in terms of the leading empirical orthogonal function (EOF) and principal component (PC) time series (with positive values indicating a delayed onset), for the CMAP (panel a) and 76station (panel b) datasets. The leading mode accounts for $27.6 \%$ of the interannual variance in the CMAP and $32.1 \%$ in the 76 -station dataset; the second EOF explains less than $9 \%$ of the variance in both cases. The EOF patterns show positive values almost everywhere across the Philippines. 
Station loadings tend to be largest over the central Philippines, even along the east coast, while CMAP loadings are largest between $5^{\circ} \mathrm{N}$ and $15^{\circ} \mathrm{N}$, broadly consistent with the station data. Figure 5a also shows the leading EOF of $850 \mathrm{hPa}$ May monthly mean winds, whose PC time series is well correlated with that of the leading mode of onset date. A delayed (early) onset is strongly related with large-scale easterly (westerly) anomalies across the Philippines, with a strong zonal wind component between $5^{\circ} \mathrm{N}$ and $20^{\circ} \mathrm{N}$. The PC timeseries of the two rainfall datasets are highly correlated $(\mathrm{r}=0.90)$ over the common 1979-2004 period (panel b).

The leading PC of the station data shows large delays in onset in $198319871992-19931998$ and 2002 (all warm ENSO or ENSO+1 years) and large advances in 1988-891994 19961999 and 2000 (not exclusively cold ENSO years). Composite anomalies of May $850 \mathrm{hPa}$ vector wind in the reanalysis for the 7 coldest ENSO events (1988 19992000198519891984 2003; Fig 6b) and 7 warmest events (1992 19831993199719981987 1982; Fig. 6c) show that the wind anomalies associated with cold ENSO events are weak and barely significant, but the cyclonic anomaly centre over the SCS is associated with an enhanced westerly-southwesterly flow to the west of the Philippines (Fig. 6b). The wind anomalies associated with warm ENSO events are generally larger with a southwestward extension of the North Pacific anticyclone leading to an anomalous easterly component of the flow south of $12^{\circ} \mathrm{N}$, associated with the delayed monsoon onset across Philippines (Wu and Wang 2000 2001; Chou et al 2003; Mao et al 2004).

Monsoon onset in this paper is based on a local agronomic definition. The onset definition used operationally by PAGASA is the beginning of the first five-day period (in April, May, June or July) with total rainfall of $25 \mathrm{~mm}$ or more, including three days of at least $1 \mathrm{~mm} /$ day; these conditions are required by PAGASA to be met at 5 or more of 9 selected western stations in Type 
I climate (black dots in Fig. 2a). In addition, it is at the discretion of PAGASA to include elements such as rainfall amounts, clustering of rainy days, area covered and wind system (prevailing winds over the western Philippines should have westerly components from the surface up to $850 \mathrm{hPa}$ level).

Figure 7 shows the correlation between time series of the operational definitions of onset issued by PAGASA, and the agronomical station onsets constructed in section $4 \mathrm{~b}$. The station correlations are noticeably smaller than those associated with the leading PC of all 76 station agronomic onsets (the median correlation in Fig. 7a is 0.24 , compared to 0.59 in Fig. 5 b). This difference arises partly by construction because the agronomic definition is used twice in Fig. 5b, both to determine the PC and the local series, whereas the PAGASA definition used in Fig. 7a is calculated independently. Nevertheless, the difference is larger than expected. The time series of the PAGASA onset definition and leading PC (Fig. 7b) exhibit several large differences (e.g. 1982-83 1985, and from 1995) that considerably reduce the correlation between them $(r=0.41)$. The correlation is slightly stronger if we consider only the stations belonging to climate Type I ( $\mathrm{r}$ $=0.54)$.

\section{b. Sampling uncertainty}

In order to help interpret the above difference between onset definitions, we next analyze systematically the sensitivity of onset date to spatial sampling. Figure 8 shows the median and inter-quartile range (IQR) of correlations (black) between the time series of onset dates averaged over random subsets of stations, with the onset-date time series averaged over the full set of 76 stations. The station averages were computed by first standardizing each station's time series by its interannual standard deviation after subtracting its mean, so as to form a standardized anomaly 
index (SAI; Katz and Glantz 1986). The correlation ranges in Fig. 8 were derived from 1000 randomly-chosen combinations of 2 through 10 stations (i.e. random draws with replacement). For a sample of 5 stations, for example, $75 \%$ of random selections of 5 stations from the full set of 76 are correlated $>0.76$ with the estimate of large-scale onset signal. Thus, any randomlychosen sample of 5 stations is likely to be sufficient to capture the large-scale onset, and even 3 stations generally yield a valuable estimator. An even more flexible approach was also considered by choosing randomly a set of 2 through 10 stations every year. This is equivalent to taking a small group of the 76 stations to provide an estimate of large-scale onset in any given year. The resulting behaviour is highly similar to that in Fig. 8.

The relative weak relationship between the operational onset defined by PAGASA and the largescale onset defined here by the 76-station SAI deserves further comment. The red circle and error bar in Fig. 8 shows the median and IQR of the correlations between the 76-station SAI and the onset based on 5 out of the 9 stations considered in the official PAGASA definition. Correlations based on the operational definition are clearly smaller than those for randomly sampled combinations of 5 stations. In other words, the particular subset of 9 stations used by PAGASA in its operational onset definition is poorly suited to capturing the large-scale onset signal. Even the SAI based on all 9 stations correlates at "only" 0.75 with the large-scale SAI, while $75 \%$ of random-samples of 9 stations exceed 0.86 . Possible reasons for these discrepancies are discussed in section 7 .

\section{c. Regional variability in onset}

From the perspective of climate risk management it is important to quantify the spatial coherence - and thus potential predictability - of onset within specific sub-regions of the 
Philippines. Here we consider, as an example, two groups of stations within Type I climate and which coincide with important rice production areas. The first group, referred to hereafter as Western Luzon (WL) includes all 15 Type I stations north of Mindoro, while the second group, referred to hereafter as Central Philippines (CP) includes 7 Type I stations located from southern Mindoro to Western Panay (Fig. 1). CP shows a higher degree of spatial coherence as measured by the interannual variance (0.54) of the SAI (Katz and Glantz 1986; Moron et al 2006 2007b) compared with 0.29 for WL (Fig. 9). This is consistent with the larger spatial coherence in the central Philippines shown by EOF 1 of onset dates in Fig. 5b. Nonetheless, both regional SAIs are strongly correlated with the 76-station SAI ( $\mathrm{r}=0.81$ for $\mathrm{WL}$ and 0.87 for $\mathrm{CP})$. Even though the 76-station SAI includes the information of the 15 stations of WL and the 7 stations of CP, this suggests that a regional-scale average of local-scale onset is strongly related to the large-scale signal, while the amount of local-scale noise can be large, as for WL (Fig. 9a).

\section{Seasonal predictability of monsoon onset}

\section{a. Forecast methods for local onset date}

The results reported in the previous section demonstrate that interannual variability of stationscale onset date exhibits some spatial coherence and is highly correlated with the large-scale wind field, suggesting potential predictability. Here we investigate seasonal forecast skill of onset date using several sets of retrospective forecasts. Multiple linear regression using CCA is utilized to construct retrospective forecasts of local monsoon onset date based on (i) observed March SST in the Tropical Indian and Pacific Oceans $\left(80^{\circ} \mathrm{E}-100^{\circ} \mathrm{W}, 20^{\circ} \mathrm{S}-20^{\circ} \mathrm{N}\right)$ and (ii) predicted ensemble-mean May monthly mean $850 \mathrm{hPa}$ wind fields $\left(110^{\circ}-135^{\circ} \mathrm{E}, 0^{\circ}-25^{\circ} \mathrm{N}\right)$ from $3 \mathrm{GCM}$ ensembles initialized on April $1^{\text {st }}$ of each year (available period is 1977-2004 for ECHAM-CA 1980-2001 for ECHAM-MOM and 1981-2001 for CFS). The CCA was performed under cross- 
validation where 3 years were withheld and the hindcast performed for the central year only. The predictor and predictand fields were pre-filtered using PC analysis, with the number of modes retained in the prefiltering and subsequent CCA determined under cross-validation so as to maximize the skill using the Climate Predictability Tool (CPT) software developed at IRI (http://iri.columbia.edu/outreach/software). Typically, 1 to 3 PCs were retained for each field leading to a maximum of 2 CCA modes for the hindcasts.

\section{b. Potential sources of skill}

The leading CCA mode of the analysis based on March SST is shown in Fig. 10. The homogeneous correlation map of SST (panel a) shows a classical ENSO pattern across the equatorial Pacific, together with high correlations over the northwestern tropical Pacific and eastern equatorial Indian Ocean that suggest the importance of additional air-sea interactions in these latter regions. The corresponding time series (panel c, blue line) indicates that warm, ENSO-like conditions are typically related to a delayed onset across the Philippines. The homogeneous correlation map of onset dates (panel b) exhibits largest correlations generally over the central Philippines, roughly consistent with the spatial coherence results in Fig. 5b. The canonical correlation for the leading mode is 0.91 . The second mode (not shown) does not substantially enhance forecast skill; it has a mean squared homogeneous correlation of only $8.2 \%$ (vs. 33.2\% for the leading mode) and a canonical correlation of 0.69 .

The three GCM ensembles each yield a leading CCA mode that is quite similar in spatial structure (not shown); in each case the homogeneous correlation maps of May 850-hPa wind are quite similar to the leading EOF of reanalyzed May winds (Fig. 5a), while the associated 
homogeneous correlation maps of onset date resemble those in Fig. 10b. The leading CCA time series of wind for the three GCMs are correlated $>0.86$ with the leading CCA mode of SST.

\section{c. Predictive skill}

Hindcast skill at each station is shown in terms of anomaly correlation coefficient between forecast and observed onset and hit skill score in Figs. 11 and 12 respectively. Here the latter indicates the relative frequency, beyond that expected by chance, that the forecast tercilecategory of the onset date (i.e. earlier-than-normal, near-normal, later-than-normal) corresponded with the observed one. The median of these scores across the 76 stations, together with the scores computed from the SAI of onset date are given in Table 2 for each of the forecast models. Skill scores for various regional values of the SAI for onset date are given in Table 3.

Skill levels by both metrics are broadly similar across the 4 forecast models, with generally slightly higher values given by the purely statistical scheme based on antecedent SST. The average correlation scores for western and eastern Philippines and for the four climate types in Table 3 are similar to each other. Nevertheless, there is a tendency for higher correlation and hit skill scores across the central Philippines from central-southern Luzon to northern Mindanao (Figs, 11, 12). The correlations are lower over NW Luzon and scattered stations in the south and all schemes behave similarly. Note that hit scores are positive over NW Luzon. As expected, the scores decrease in proportion with the spatial scale of average but values for WL and CP are still largely significant.

\section{Summary and discussion}

a. Summary 
This paper has analyzed the summer monsoon onset date and its interannual variability across the Philippines, using a local agronomic definition applied to daily station rainfall data and gridded CMAP pentad estimates. The median onset date across years is very close to the mean, and varies between April 5 and June 26 across the 76 stations. Median onset occurs about 15 days earlier in the Type II climate in the east than in the Type I climate in the west (Fig. 3; Table 1). Higher elevations tend to have earlier onset than surrounding lowlands, probably because orographic uplift enhances convection thus meeting the onset criteria sooner. The latest onset dates are typically observed along the western coast and for the inner islands (Visayan, Bohol etc.) of the central Philippines, the latter having either relatively flat topography or being located in rainshadowed locations. The larger-scale northward progression of rainfall in the CMAP appears to be weak over the Philippines, and to be obscured by local effects in the station data.

Interannual variability at the station scale was found to be more spatially coherent over the central Philippines, measured in terms of the leading EOF, while CMAP EOF loadings were found to be largest between $5^{\circ} \mathrm{N}$ and $15^{\circ} \mathrm{N}$, consistent with the station data (Fig. 5). Regional station indices for Western Luzon (WL) and the Central Philippines (CP) indicate a higher degree of spatial coherence in the latter, as measured by the interannual variance $(0.54)$ of the SAI compared with 0.29 for WL (Fig. 9).

Multiple linear regression using CCA was used to construct retrospective forecasts of local monsoon onset date based on (i) observed March SST and (ii) predicted May 850hPa wind fields from 3 GCM ensembles initialized on April $1^{\text {st }}$ of each year. Skill in terms of anomaly correlation coefficient and hit skill scores is found to be similar in all models, if slightly higher using antecedent SST as predictor. Skill levels are found to increase rapidly with spatial aggregation of 
stations, with anomaly correlation hindcast skills of $0.50-0.83$ across the set of models and spatial aggregates considered (Table 3). There is a tendency toward higher skill across the central Philippines from central-southern Luzon to northern Mindanao, and lower over NW Luzon (Figs, $11,12)$, consistent with higher spatial coherence there. The leading CCA mode for the analysis based on March SST exhibits a classical ENSO SST pattern, in addition to high correlations over the WNP and eastern equatorial Indian Ocean.

\section{b. Discussion}

According to our results, the onset of the summer monsoon at the station scale over the Philippines emerges as the local-scale expression of larger-scale changes, related to the multistage advance of the South and East Asia monsoon and associated with a northeastward contraction of the North Pacific subtropical anticyclone and concomitant development of SW flow at low levels across the SCS and the Philippines (Fig. 4c,d), as well as the strengthening of the upper-level anticyclone over the south Asian land mass (e.g. Wu and Wang 2000 2001; Liu et al 2001 2002; Wu et al 2007). This is consistent with the rapid onset across the entire Philippines, despite being less clear over the eastern Philippines due to its exposure to moist easterly flow. Thus, onset over the Philippines has a different character than that over Indonesia (Moron et al 2008), or even the Sahel (Marteau et al 2008) where it appears as a seasonal migration across the domain.

The strongest spatial coherence of interannual variability in onset is found over the central Philippines, between northern Mindanao and southern Luzon, and in a belt between $10^{\circ}-13^{\circ} \mathrm{N}$ in the CMAP data. It could be argued that the higher EOF loadings in the central part of the domain are an artefact linked to the domain used. This was checked by estimating the mean correlations 
between stations within radii of $150-300 \mathrm{~km}$; these were found to exhibit higher values over the central Philippines (not shown), corroborating the EOF result. The stronger spatial coherence there may be associated with this region being the most protected from the low-level easterly flow prior to onset (see for example the mean rainfall $<25 \mathrm{~mm} 10$ days before the large-scale onset on Fig. 4b); the onset signal may thus be cleaner than elsewhere. More work is needed to understand the local-scale mechanisms of spatial coherence, such as through the use of a highresolution regional model.

The interannual variability captured by the leading PC of CMAP and PAGASA datasets are well correlated with other regional-scale estimates previously published for adjacent regions, but using different methodologies and datasets to define the onset of the rainy season. For example, the leading PC of the 76-stations and CMAP data are both correlated at 0.62 with the mean regionalscale onset date averaged across central Indochina (where onset is defined from daily rainfall averaged across 30 stations in $96^{\circ} \mathrm{E}-105^{\circ} \mathrm{E} 10^{\circ}-20^{\circ} \mathrm{N}$ ) on the $1979-1996$ common period (Zhang et al. 2004). The correlations are higher ( 0.78 for 76 -stations and 0.74 for CMAP) with the OLRindex defining the onset of the boreal monsoon over SCS (where onset is defined as the first day when mean OLR averaged over $5^{\circ}-20^{\circ} \mathrm{N}, 110^{\circ}-120^{\circ} \mathrm{E}$ is less than $230 \mathrm{~W} / \mathrm{m}^{2}$ ) on the common 1979-2001 period (Mao et al 2004). Note that the correlation with this latter index reaches 0.86 for the average of the Type I climate stations, located close to the SCS. This suggests that, despite different methodologies and datasets used to define it, and also beyond the internal "noise" between nearby stations, the large-scale onset across Indochina-SCS and central Philippines probably belongs to the same phenomenon, strongly modulated by ENSO. 
The large-scale spatial coherence in onset date has potential implications for the monitoring of onset conditions in near real-time. Daily rainfall observations for a large set of stations may be difficult to obtain in real time. However, a random set of 5 or 6 stations was found give an accurate estimate of the large-scale onset (Fig. 8). It is not even necessary to take the same set of stations every year for this purpose, due to the efficient cancellation of the inter-station noise (cf. Moron et al 2006, 2007a). From a practical point of view, it is encouraging that a robust estimate of the large-scale summer monsoon onset can be provided by a small number of stations.

A primary consideration in our choice of monsoon onset definition was to choose a local definition amenable to end-user purposes that would not artificially inflate estimates of spatial coherence; the latter could then be used as a measure of potential predictability. Previous studies in other areas (e. g., the western and central Sahel: Marteau et al 2008; Indonesia: Moron et al 2008) have shown that the details of the criteria used to define onset date-while having an impact on the mean onset date- have only weak impact on its interannual variability. However, for applied purposes, such as the impact of monsoon onset on crop yields, the parameters should nonetheless be tuned to the purpose at hand.

The all-Philippines onset dates identified operationally by PAGASA were not found to be strongly correlated in time with our agronomic onset dates at individual stations. The agronomic definition used here is not necessarily better than the operational PAGASA definition as any definition is subjective, constrained by sampling choices and data availability. In addition, the onset definition of greatest practical utility may not necessarily be well correlated with a largescale measure of monsoon onset. Our estimate of large-scale onset in terms of the leading EOF of station agronomic onsets is clearly biased toward the latter, compared to the PAGASA definition 
that is independent of the agronomic definition. However, the set of up to 9 stations used by PAGASA are all located close to the west coast and all belong to climate Type I (Fig. 2a), and were shown to be less efficient at sampling the phase of the 76 stations, compared to a random sample of 9 stations selected from across the entire country. It may thus be preferable to sample as uniformly as possible across the Philippines. In addition, the mean correlation was computed between agronomic onset at each station with all other stations in a radius of $150 \mathrm{~km}$. The median of these correlations equals 0.35 (with a median distance of $94 \mathrm{~km}$ ) for the 76 stations and only 0.25 (for a median distance of $88 \mathrm{~km}$ ) for the 9 stations considered in the operational PAGASA definition. In other words, the spatial coherence is weaker in the latter, than for most other 9station samples. This could be due to the large-scale modulation of onset signal that is strongest over the central Philippines, and/or the impact of small-scale orography, especially for rain gauges located along the western coast of North Luzon (Fig. $1 \& 2 a$ ).

Encouraging cross-validated hindcast skill of onset date was identified with a cross-validated correlation of 0.83 for the all-station case; considering any random pool of at least 7-9 stations leads to a similar level of skill but skill at individual stations is necessarily lower. Boreal spring remote SSTs in the equatorial central-eastern Pacific and local SST over the Tropical WNP clearly have a significant impact on onset (Wang et al 2000; Wu and Wang 2000 2001), despite the ENSO spring predictability barrier. The GCM-based "downscaled" predictions were not found to outperform the simple antecedent SST-based scheme, though results were generally quite similar. The use of May-average $850-\mathrm{hPa}$ GCM wind fields as the predictor in CCA may present a limitation here; further work is required to develop optimal methods for downscaled predictions of onset dates. In all cases, skill can be substantially different between nearby stations, and again further work is required to determine the sources of this noise. 


\section{Acknowledgments}

This research was supported by grants from the National Oceanic and Atmospheric Administration (NOAA), NA050AR4311004, the US Agency for International Development's Office of Foreign Disaster Assistance, DFD-A-00-03-00005-00, and the US Department of Energy's Climate Change Prediction Program, DE-FG02-02ER63413.The computing for this project was partially provided by a grant from the NCAR CSL program to the IRI. The NCEP CFS model runs were obtained from the U.S. Climate Prediction Center via the IRI Data Library. We wish to acknowledge the valuable contributions of Ms. Remedios Liwanag who help compile and quality control the daily rainfall data used in this research study. We also thank the Philippine Atmospheric Geophysical and Astronomical Services Administration (PAGASA) for providing the daily rainfall records, and many thanks to the staff of the Climate Data Section of the Climatology and Agrometeorology Branch of PAGASA for their helpful efforts during the station selection. Lastly, we thank Simon Mason (IRI) for his help with CPT and Leo Ostwald (IRI) for his help in obtaining GCM runs.

\section{References}

Akasaka I, Morishima W, Mikami T (2007) Seasonal march and its spatial difference of rainfall in the Philippines. Int J Climatol 27: 715-725.

Chang CP, Chen GTJ (1995) Tropical circulations associated with southwest monsoon onset and westerly surges over the South China Sea. Mon Wea Rev 123: 3254-3267.

Chou C, Tu JY, Yu JH (2003) Interannual variability of the western North Pacific summer monsoon: differences between ENSO and Non-ENSO years. J Clim 16: 2275-2287. 
Coronas J (1920) The climate and weather of the Philippines, 1903 to 1918. Bureau of printing, Manila, 195 pp.

DeWitt DG (2005) Retrospective forecasts of interannual sea surface temperature anomalies from 1982 to present using a directly coupled atmosphere-ocean general circulation model, Mon Wea Rev 133: 2972-2995.

Diday E, Simon JC (1976) Clustering analysis. In Digital Pattern Recognition, Fu KS (ed.), Communication and Cybernetics, vol. 10. Springer-Verlag: 47-94.

Ding Y (2004) Seasonal March of the East-Asian Summer Monsoon. In East Asian Monsoon, C.P. Chang, Ed., World Scientific, Singapore, 3-53.

Flores JF, Balagot VF (1969) Climate of the Philippines in World Survey of Climatology nº, Elsevier, 159-213.

Goddard L, Mason SJ, Zebiak SE, Ropelewski CF, Basher R, Cane MA (2001) Current approaches to seasonal-to-interannual climate predictions. Int J Climatol. 21: 1111-1152.

Jose AM, Cruz NA (1999) Climate change impacts and responses in the Philippines: water resources. Clim Res 12: 77-84.

Katz RW, Glantz MH (1986) Anatomy of a rainfall index. Mon Wea Rev 114: 764-771.

Kalnay E, Kanamitsu M, Kistler R, Collins W, Deaven D, Gandin L, Iredell M, Saha S, White G, Woollen J, Zhu Y, Chelliah M, Ebisuzaki W, Higgins W, Janowiak J, Mo KC, Ropelewski C, Wang J, Leetmaa A, Reynolds R, Jenne R, Joseph D (1996) The NCEP-NCAR 40-year reanalysis project. Bull Amer Soc 77: 437-471.

Kiladis GN, Diaz HF (1989) Global Climatic Anomalies Associated with Extremes in the Southern Oscillation, J Clim 2: 1069-1090.

Kintanar RL (1984) Climate of the Philippines, PAGASA report, $38 \mathrm{pp}$. 
Lau KM, Yang S (1997) Climatology and interannual variability of the osutheast Asian summer monsoon. Adv Atmos Sci 14: 141-162.

Li S, Goddard L, DeWitt DG (2008) Predictive skill of AGCM seasonal climate forecasts subject to different SST prediction methodologies. J Clim 21: 2169-2186.

Liu YM, Wu GX, Liu H, Liu P (2001), Condensation heating over the Asian summer monsoon and the subtropical anticyclone in the Eastern Hemisphere. Clim Dyn 17: 327-338.

Liu YM, Chan JCL, Mao JY, Wu GX (2002) The role of Bay of Bengal convection in the onset of the 1998 South China Sea summer monsoon. Mon Wea Rev 130: 2731-2744.

Lyon B, Cristi H, Verceles ER, Hilario FD, Abastillas R (2006) Seasonal Reversal of the ENSO Rainfall Signal in the Philippines. Geophys Res Let, 33 L24710, doi:10.1029/2006GL028182.

Lyon B, Camargo S (2008) The seasonally varying influence of ENSO on rainfall and tropical cyclone activity in the Philippines. Clim Dyn, in press (published online 26 February 2008).

Mao J, Chan JCL, Wu G (2004) Relationship between the onset of the south China sea summer monsoon and the structure of the Asian subtropical anticyclone, J Meteo Soc Japan 82: 845-859.

Marteau R, Moron V, Philippon N (2008) Spatial coherence of boreal monsoon onset across Sahel. J Clim, in press.

Moron V, Robertson AW, Ward MN (2006) Seasonal predictability and spatial coherence of rainfall characteristics in the tropical setting of Senegal, Mon Wea Rev 134: 3248-3262.

Moron V, Lucero A, Hilario F, DeWitt D, Lyon B, Robertson AW (2007a) Seasonal predictability of monsoon onset over the Philippines, CLIVAR exchanges n³5, pp. 14-19. Moron V, Robertson AW, Ward MN, Camberlin P (2007b) Spatial coherence of tropical rainfall at the regional scale. J Clim 20: 5244-5263.

Moron V, Robertson AW, Boer R (2008) Spatial coherence and seasonal predictability of monsoon onset over Indonesia. J Clim, in press. 
Murakami T, and Matsumoto J. (1994) Summer monsoon over the Asian continent and western North Pacific. J Meteo Soc Japan 72: 719-745.

Ropelewski CF, Halpert MS (1987) Global and regional scale precipitation patterns associated with the El Niño southern Oscillation. Mon Wea Rev 115: 1606-1626.

Ropelewski CF, Halpert MS (1996) Quantifying Southern Oscillation - Precipitation relationships. J Clim 9: 1043-1059.

Saha S, Nadiga S, Thiaw C, Wang J, Wang W, Zhang Q, Van den Dool HM, Pan HL, Moorthi S, Behringer D, Stokes D, Pena M, Lord S, White G, Ebisuzaki W, Peng P, Xie P (2006) The NCEP climate forecast system. J Clim 19: 3483-3517.

Sivakumar MVK (1988) Predicting rainy season potential from the onset of rains in southern Sahelian and Sudanian climatic zones of West-Africa. Agric For Meteo 42: 295-305.

van den Dool, HM (1994) Searching for analogues, how long must we wait ? Tellus 46A: 314324.

Wang B (1994) Climatic regimes of tropical convection and rainfall. J Clim 7: 1109-1118.

Wang B, Wu R, Fu X (2000) Pacific-East Asian teleconnection : how does ENSO affect East Asian climate ? J Clim 13: 1517-1536.

Wang B, LinHo (2002) Rainy season of the Asian-Pacific summer monsoon. J. Clim 15: 386398.

Wang B, Zhang Q (2002) Pacific-East Asian Teleconnection. Part II: How the Philippine Sea anomalous anticyclone is established during El Niño development. J Clim 15: 3252-3265.

Webster PJ, Magana VO, Palmer TN, Tomas TA, Yanai M, Yasunari T (1998) Monsoons : processes, predictability and prospects for prediction. J Geophys Res 103: 14451-14510.

Wilks DS (1999) Interannual variability and extreme-value characteristics of several stochastic daily precipitation models. Agric For Meteo 93: 153-169. 
Wu GX, Zhang YS (1998) Tibetan plateau forcing and the timing of the monsoon onset over South Asia and the South China Sea. Mon Wea Rev 126: 913-927.

Wu GX, Liu YM, Wang TM, Wan R, Liu X, Li W, Wang Z, Zhang Q, Duan A, Liang X (2007) The influence of the mechanical and thermal forcing of the Tibetan plateau on the Asian climate. J Hydrometeo 8: 770-789.

Wu R, Wang B (2000) Interannual variability of summer monsoon onset over the Western North Pacific and the underlying processes. J Clim 13: 2483-2501.

Wu R, Wang B (2001) Multi-stage onset of the summer monsoon over the western North Pacific. Clim Dyn 17: 277-289.

Xie P, Arkin PA (1997) Global precipitation: A 17-year monthly analysis based on gauge observations, satellite estimates and numerical model outputs. Bull Amer Meteo Soc 78: 25392558.

Xie P, Arkin PA (1998) Global monthly precipitations estimates from satellite-observed outgoing longwave radiation. J Clim 11: 137-164.

Yasunari T (1991) The monsoon year - a new concept of the climatic year in the tropics. Bull Amer Meteo Soc 72: 1331-1338.

Zhang Z, Chan CL, Ding Y (2004) Characteristics, evolution and mechanisms of the summer monsoon onset over southeast Asia. Int J Climatol 24: 1461-1482. 


\section{Figure captions}

Figure 1: Location of the 76 stations with shadings representing altitude 500-1000 m (light gray), 1000-2000 m (medium gray) and $>2000 \mathrm{~m}$ (black). The colours refer to the modified Coronas climate classification of the Philippines (Coronas 1920; Flores and Balagot 1969; Kintanar 1984). Red dots represent Type I climate (two pronounced season with dry period from November to April and wet period from May to October) ; Blue dots represent Type II climate (no dry season with a very pronounced maximum rainfall during the moths of November to December); Yellow dots represent Type III climate (seasons not very pronounced with a relatively dry period from November to April, as in Type I); Green dots represents Type IV climate with rainfall more or less evenly distributed along the year.

Figure 2: (a) 2-cluster solution of $k$ means clustering of daily rainfall at the 76 stations. The daily rainfall amounts are averaged across the year and then low-pass filtered to retain only variations slower than 1/120 cycle-per-day. The 9 stations retained in the PAGASA definition (i.e. from North to South, Vigan, Laoag, Iba, Dagupan, Sangley (Manila Metropolitan Area), S. Garden (Manila Metropolitan Area), Ambulong, San José and Iloilo) are identified with a black dot. (b) low-pass mean seasonal cycle of rainfall amount for the Western Philippines (i.e. red circle in panel (a)) with the spatial mean as black line. (c) same as (b) except for the Eastern Philippines (i.e. blue circle in panel (b)).

Figure 3: 25\%, 50\% and 75\% percentiles of CMAP (a-c) and rain gauge (d-f) local-scale onset dates.

Figure 4: Composite raw winds at $850 \mathrm{hPa}$ (arrows) and mean CMAP rainfall amounts (shadings) (in 10 days) for the (a) 20-11 days, (b) 10-1 days before the onset and (c) 1-10 and (d) 11-20 days from the mean large-scale onset defined as the average of the 76-stations each year. The panels (e-h) show the corresponding mean rainfall amounts for the 76 stations. 
Figure 5: Leading Empirical Orthogonal Function (as expressed as loadings, that are correlations between leading principal component -PC- and grid-points/stations) in CMAP (a) and (b) raingauge stations. The leading EOF of wind at $850 \mathrm{hPa}$ in May is superimposed on panel as arrows. (c) time series of leading PC computed on the whole set of 76 stations (black line and circle), CMAP grid-points (red line with circle) and $850 \mathrm{hPa}$ wind in May (blue line and square).

Figure 6: (a) Mean wind at $850 \mathrm{hPa}$ in May according to NCEP-I, (b) Mean wind standardized anomalies at $850 \mathrm{hPa}$ in May for the 7 coldest Niño 3.4 events (i.e. from cold to warm 19881999 2000198519891984 2003). (c) Mean wind standardized anomalies at $850 \mathrm{hPa}$ in May for the 7 warmest Niño 3.4 events (i.e. from warm to cold 199219831993199719981987 1982). In panels (b) and (c), the shadings indicate significant anomalies at the two-sided $90 \%$ level according to a Student's T test computed on the difference between warm and cold samples relatively to the 14 neutral years, not included in the warm/cold years.

Figure 7: (a) Correlation of PAGASA onset (see text) and the local-scale onset defined as the first wet day of 5-day receiving $40 \mathrm{~mm}$ without 15 days receiving $5 \mathrm{~mm}$ in the following 30 days. (b) Standardized time series of the PAGASA onset (full bold line with black square) and the leading principal component of the local-scale onset in the 76-station network (dashed line).

Figure 8: Median (dashed line and circle) and inter-quartile range (error bar) of 1000 random combinations of 2 through10 stations and the Standardized Anomaly Index (SAI) of the whole set of 76 stations (in black) and of the 126 combinations of 5 stations out of the 9 selected by PAGASA to define the onset (Fig. 2a) and the correlation between the 9-stations SAI and the 76stations SAI (in red)

Figure 9: (a) Standardized anomalies (mean $=0$ and standard deviation $=1$ ) of the local-scale onset date in the 15 "Type I" stations of western Luzon in dotted lines with the spatial average (i.e. the Standardized Anomaly Index) as a full bold line with circle and the SAI of the 76 stations 
as a full line with a square. (b) same as (a) for the 7 "Type I" stations between southern Mindoro and Western Panay (Fig. 1).

Figure 10: Homogenous correlation maps of the first CCA mode between the local-scale onset (b) and the sea surface temperature (a) in March. (c) Standardized time series of the first CCA mode with the SST time series in blue and the onset time series in red with circle.

Figure 11: Correlation between observed and hindcast local-scale onset (a) from observed sea surface temperatures in March, (b) simulated mean monthly winds in May by ECHAM-CA, (c) simulated mean monthly winds in May by CFS, (d) simulated mean monthly winds in May by ECHAM-MOM.

Figure 12: Hit skill score (i.e. percentage of times beyond that expected by chance the forecast tercile corresponds with the observed tercile) of hindcast local-scale onset (a) from observed sea surface temperatures in March, (b) simulated mean monthly winds in May by ECHAM-CA, (c) simulated mean monthly winds in May by CFS, (d) simulated mean monthly winds in May by ECHAM-MOM.. 
Tables

\begin{tabular}{|c|c|c|c|c|c|}
\hline Region & $\begin{array}{l}\text { Number } \\
\text { of } \\
\text { stations }\end{array}$ & $\begin{array}{l}25 \text { th, } 50 \text { th and } \\
75 \text { th percentiles } \\
\text { of station-average } \\
\text { onset date }\end{array}$ & $\begin{array}{c}\text { Inter-quartile range } \\
\text { of station-average } \\
\text { (days) }\end{array}$ & \begin{tabular}{|c|} 
Station- \\
average \\
inter-quartile \\
range (days)
\end{tabular} & $\operatorname{Var}[\mathrm{SAI}]$ \\
\hline All stations & 76 & $\begin{array}{l}\text { May 4, May 12, } \\
\text { May } 22\end{array}$ & 18 & 34 & 0.31 \\
\hline $\begin{array}{l}\text { Western } \\
\text { Philippines }\end{array}$ & 44 & $\begin{array}{c}\text { May 7, May 20, } \\
\text { May } 26\end{array}$ & 19 & 30 & 0.31 \\
\hline $\begin{array}{l}\text { Eastern } \\
\text { Philippines }\end{array}$ & 32 & $\begin{array}{l}\text { April 27, May } \\
\text { 11, May } 18\end{array}$ & 21 & 38 & 0.38 \\
\hline Type I & 22 & $\begin{array}{l}\text { May } 11, \text { May } 21, \\
\text { May } 26\end{array}$ & 15 & 25 & 0.30 \\
\hline Type II & 17 & $\begin{array}{l}\text { April 20, April } \\
29, \text { May } 7\end{array}$ & 17 & 32 & 0.43 \\
\hline Type III & 20 & $\begin{array}{c}\text { May 5, May 20, } \\
\text { May } 31\end{array}$ & 26 & 37 & 0.39 \\
\hline Type IV & 17 & $\begin{array}{l}\text { May 5, May 18, } \\
\text { May } 28\end{array}$ & 23 & 42 & 0.36 \\
\hline $\begin{array}{l}\text { 9-stations of } \\
\text { PAGASA }\end{array}$ & 9 & $\begin{array}{l}\text { May 12, May 21, } \\
\text { May 26 }\end{array}$ & 14 & 24 & 0.36 \\
\hline
\end{tabular}

Table 1: Statistics of station onset date for all stations, and the regional groupings described in

the text: the western and eastern Philippines (Fig. 2), the four climatic types (Fig. 1) and the 9 stations used by PAGASA to define onset date. The last column gives the interannual variance of the standardized anomaly index (SAI) computed for each station group. The SAI is computed as the spatial average of standardized station time series to zero mean and unit variance (Katz and Glantz 1986). 


\begin{tabular}{|l|c|c|c|}
\hline & $\begin{array}{c}\text { Median station } \\
\text { anomaly correlation }\end{array}$ & $\begin{array}{c}\text { Median station hit } \\
\text { skill score }\end{array}$ & $\begin{array}{c}\text { Anomaly correlation } \\
\text { of SAI (all stations) }\end{array}$ \\
\hline SST & .39 & $25 \%$ & .83 \\
\hline ECHAM-CA & .28 & $20 \%$ & .76 \\
\hline CFS & .43 & $21 \%$ & .66 \\
\hline ECHAM-MOM & .32 & $18 \%$ & \\
\hline
\end{tabular}

Table 2: Summary of cross-validated hindcast skill scores for station onset dates, from the 4 different forecast schemes (see text). The rightmost column gives the anomaly correlation coefficient for the standardized anomaly index (SAI) computed by first standardizing each station's time series by its interannual standard deviation and substracting its mean and second averaging over all 76 stations (Katz and Glantz 1986).

\begin{tabular}{|l|l|l|l|l|l|l|l|l|}
\hline & Pestern & Eastern & Type I & Type II & Type III & Type IV & Western & Central \\
\hline SST & .78 & .77 & .77 & .73 & .71 & .75 & .69 & .64 \\
\hline ECHAM- & .75 & .66 & .71 & .67 & .68 & .61 & .65 & .55 \\
CA & & & & & & & & \\
\hline CFS & .79 & .71 & .75 & .69 & .77 & .67 & .65 & .66 \\
\hline ECHAM- & .64 & .60 & .61 & .59 & .62 & .50 & .54 & .52 \\
MOM & & & & & & & & \\
\hline
\end{tabular}

Table 3: Summary of cross-validated hindcast skill for the standardized anomaly index (SAI) of onset dates for the regional groupings described in the text: the western and eastern Philippines (Fig. 2), the four climatic types (Fig. 1). Western Luzon corresponds to 13 Type I stations north of $13^{\circ} \mathrm{N}$ and Central Philippines to 7 climate Type I stations south of $13^{\circ} \mathrm{N}$. 


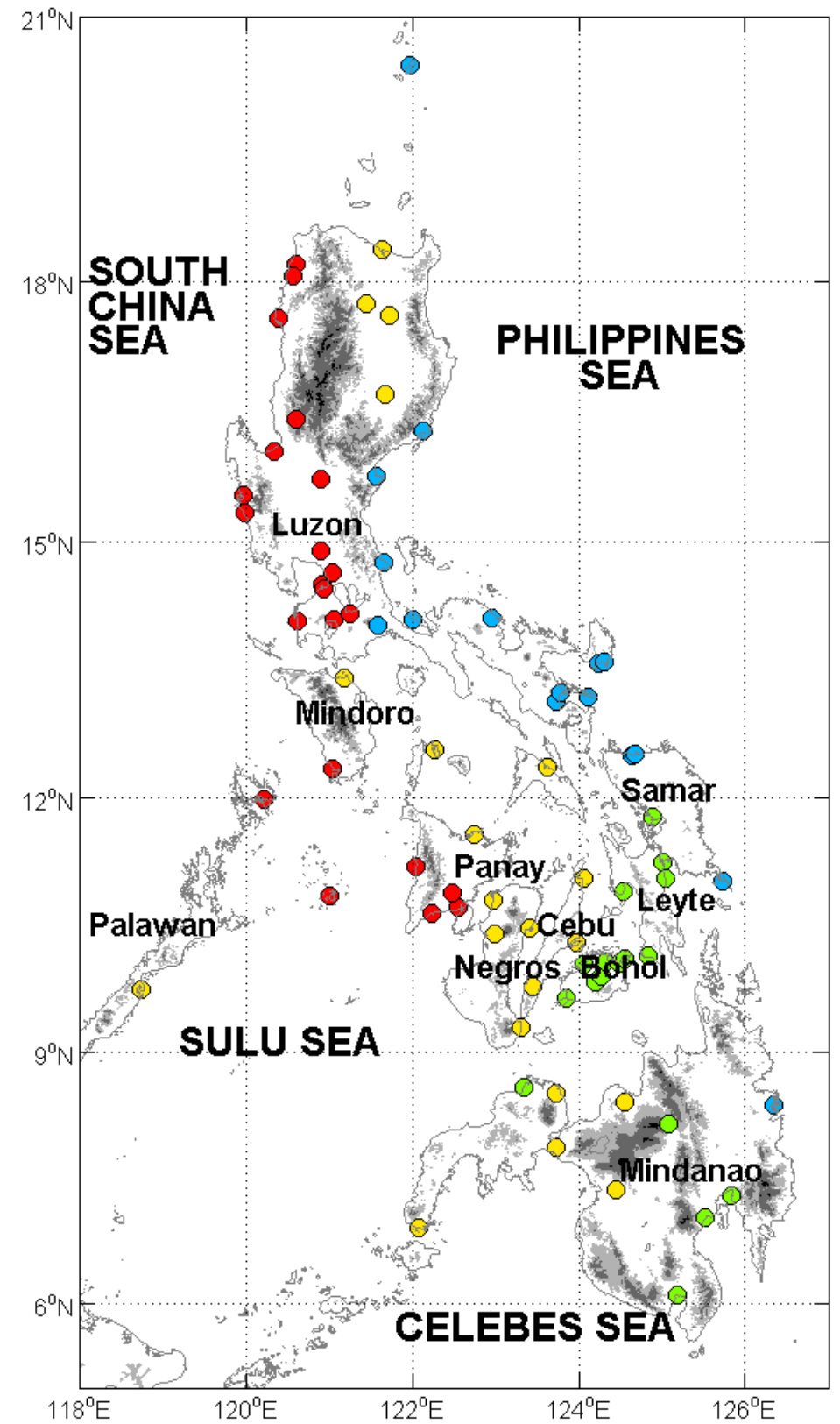




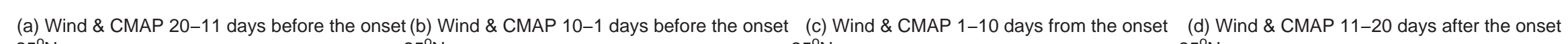

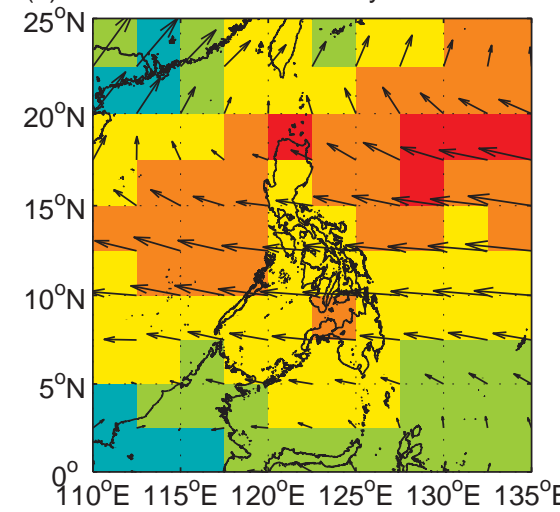

$110^{\circ} \mathrm{E} 115^{\circ} \mathrm{E} 120^{\circ} \mathrm{E} 125^{\circ} \mathrm{E} 130^{\circ} \mathrm{E} 135^{\circ} \mathrm{E}$

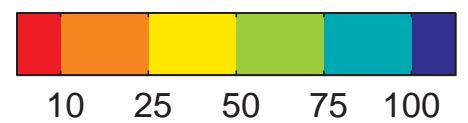

(e) Rain-gauge 20-11 days before the onset

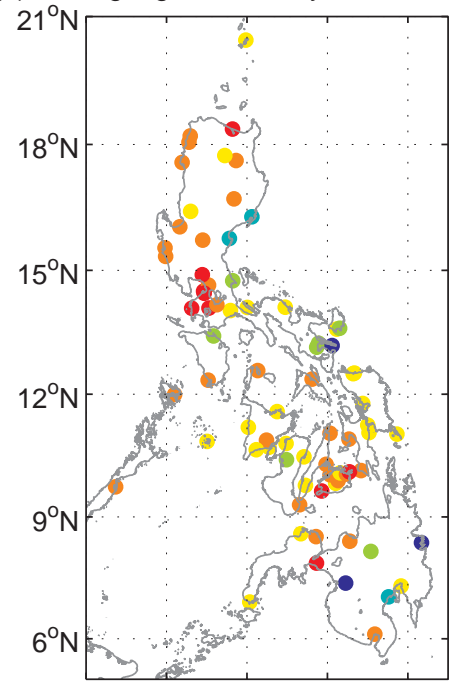

$118^{\circ} \mathrm{E} 120^{\circ} \mathrm{E} 122^{\circ} \mathrm{E} 124^{\circ} \mathrm{E} 126^{\circ} \mathrm{E}$
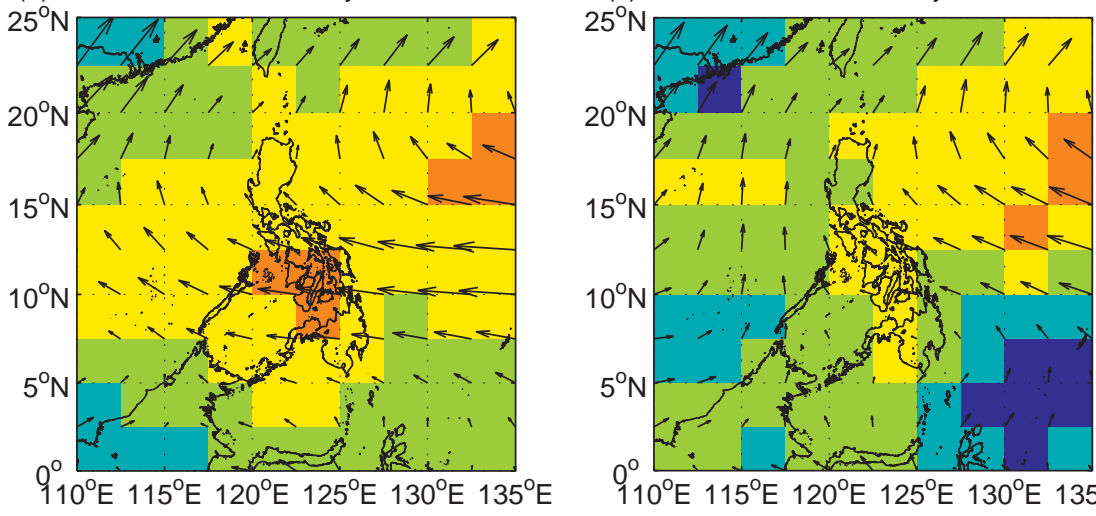

$110^{\circ} \mathrm{E} 115^{\circ} \mathrm{E} 120^{\circ} \mathrm{E} 125^{\circ} \mathrm{E} 130^{\circ} \mathrm{E} 135^{\circ} \mathrm{E}$

(f) Rain-gauge 10-1 days before the onset

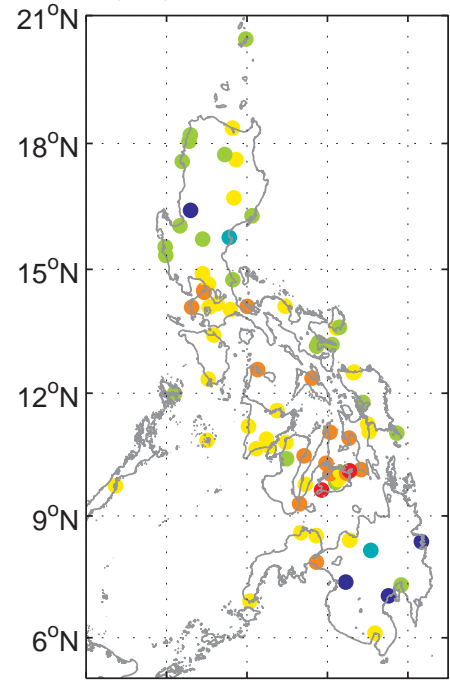

$118^{\circ} \mathrm{E} 120^{\circ} \mathrm{E} 122^{\circ} \mathrm{E} 124^{\circ} \mathrm{E} 126^{\circ} \mathrm{E}$
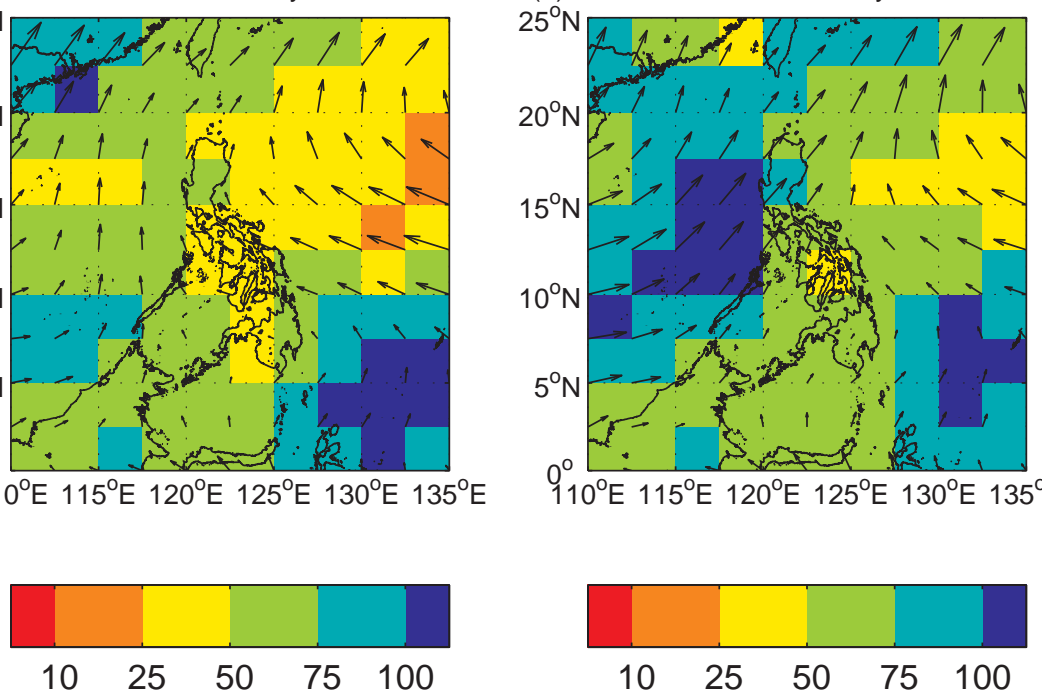

$110^{\circ} \mathrm{E} 115^{\circ} \mathrm{E} 120^{\circ} \mathrm{E} 125^{\circ} \mathrm{E} 130^{\circ} \mathrm{E} 135^{\circ} \mathrm{E}$

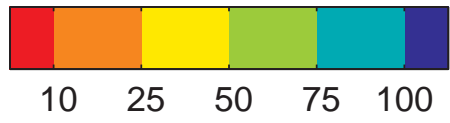

(g) Rain-gauge 1-10 days from the onset

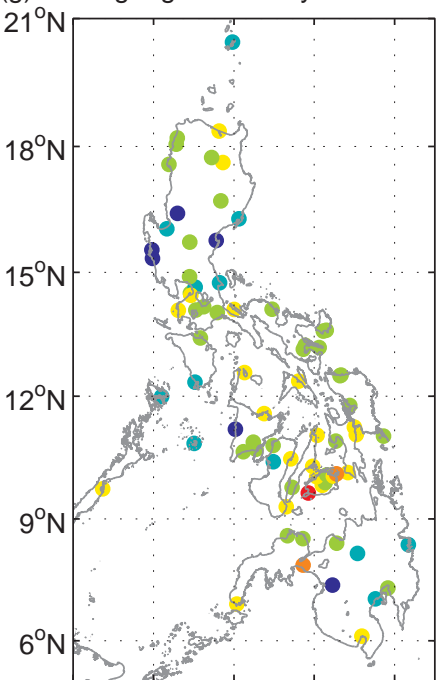

$118^{\circ} \mathrm{E} 120^{\circ} \mathrm{E} 122^{\circ} \mathrm{E} 124^{\circ} \mathrm{E} 126^{\circ} \mathrm{E}$ (h) Rain-gauge 11-20 days after the onset

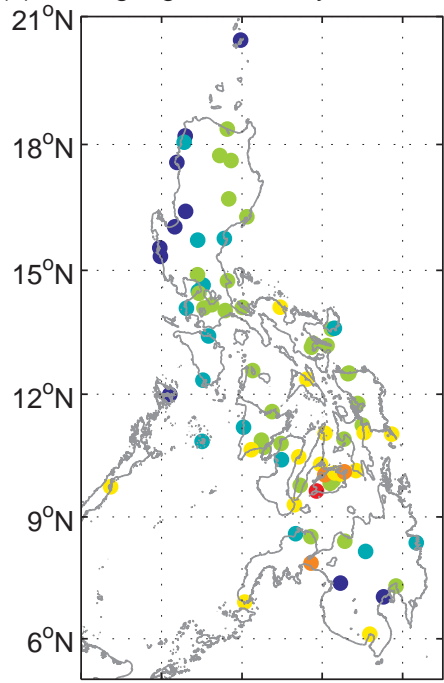

$118^{\circ} \mathrm{E} 120^{\circ} \mathrm{E} 122^{\circ} \mathrm{E} 124^{\circ} \mathrm{E} 126^{\circ} \mathrm{E}$ 


\section{(a) Western Luzon}

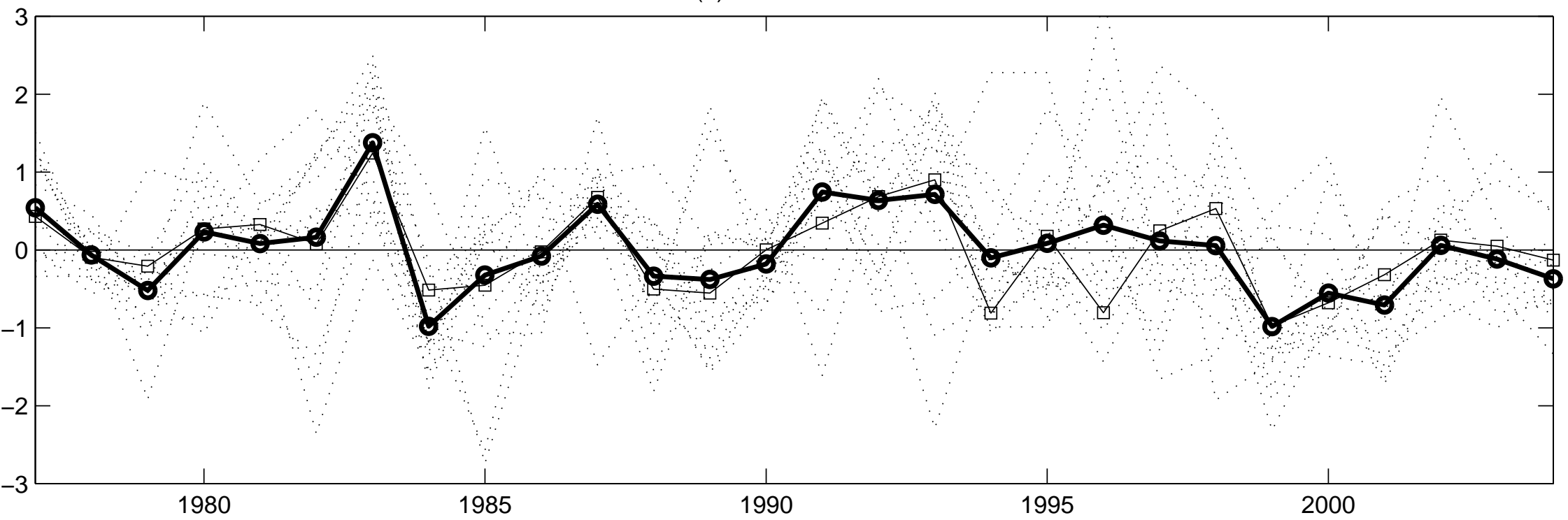

(b) West-Central Philippines

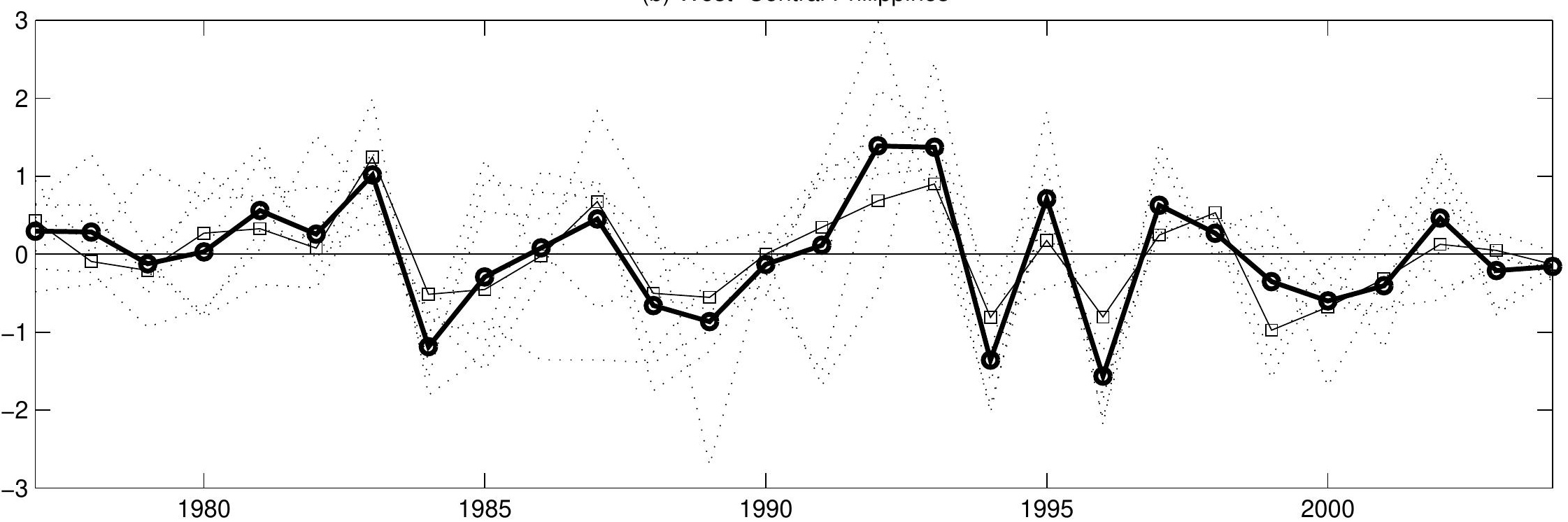


(a) Homogeneous corr. of CCA\#1 in March SST

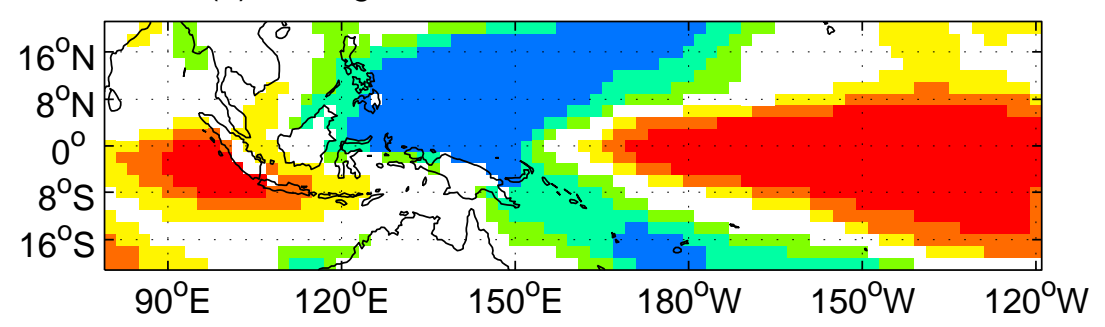

(b) Homogeneous corr. of CCA\#1 in onset date
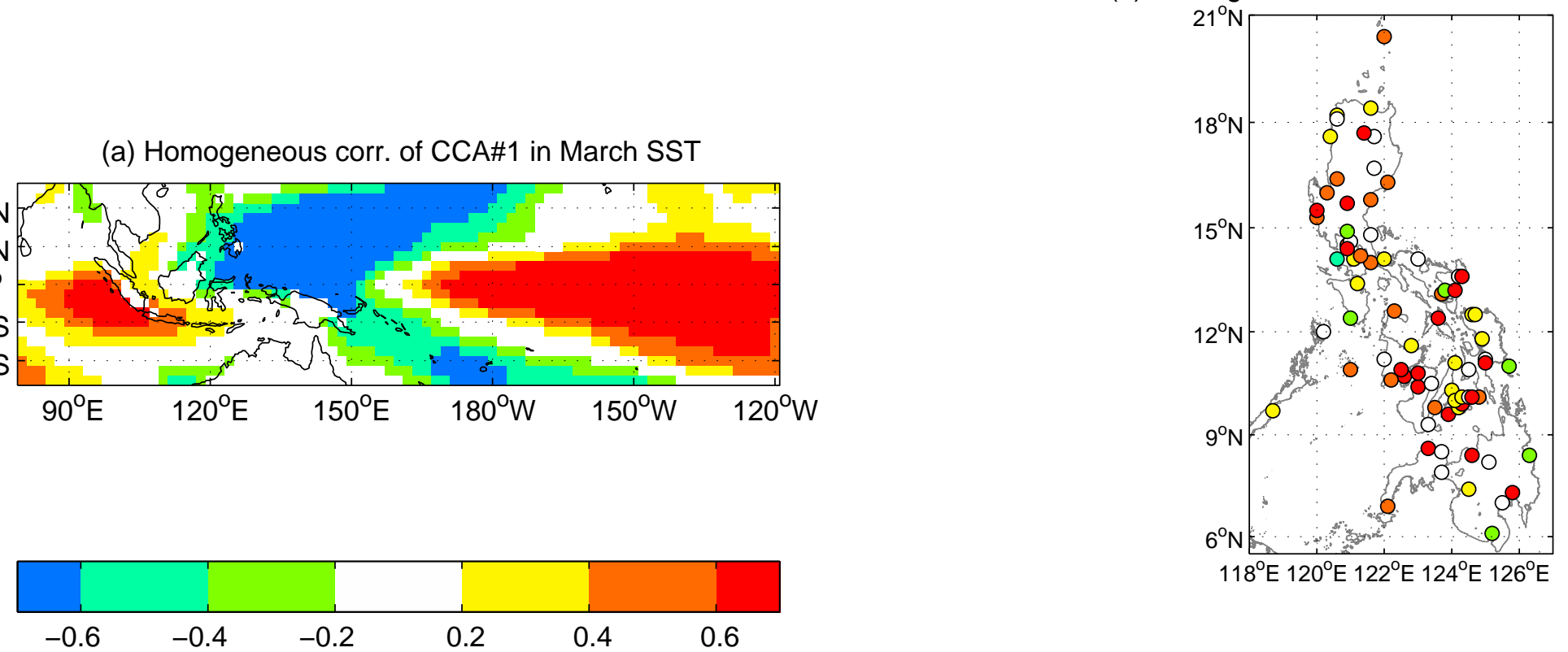

(c) Time series

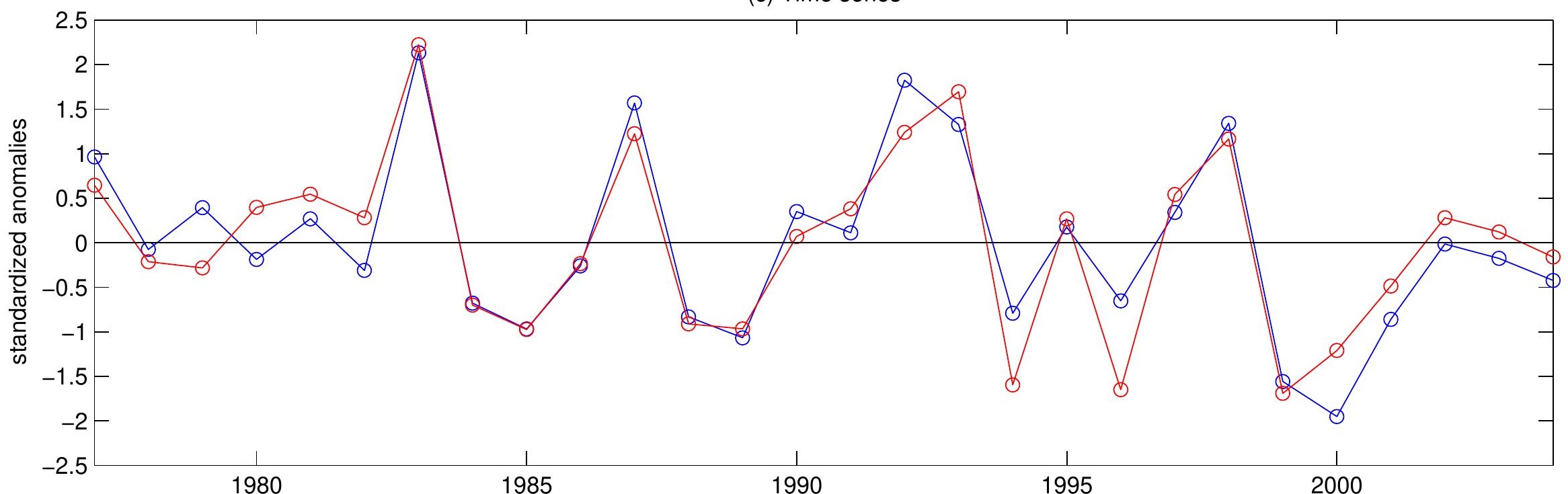


(a) Corr. hindcast (March SST) vs observed onset date

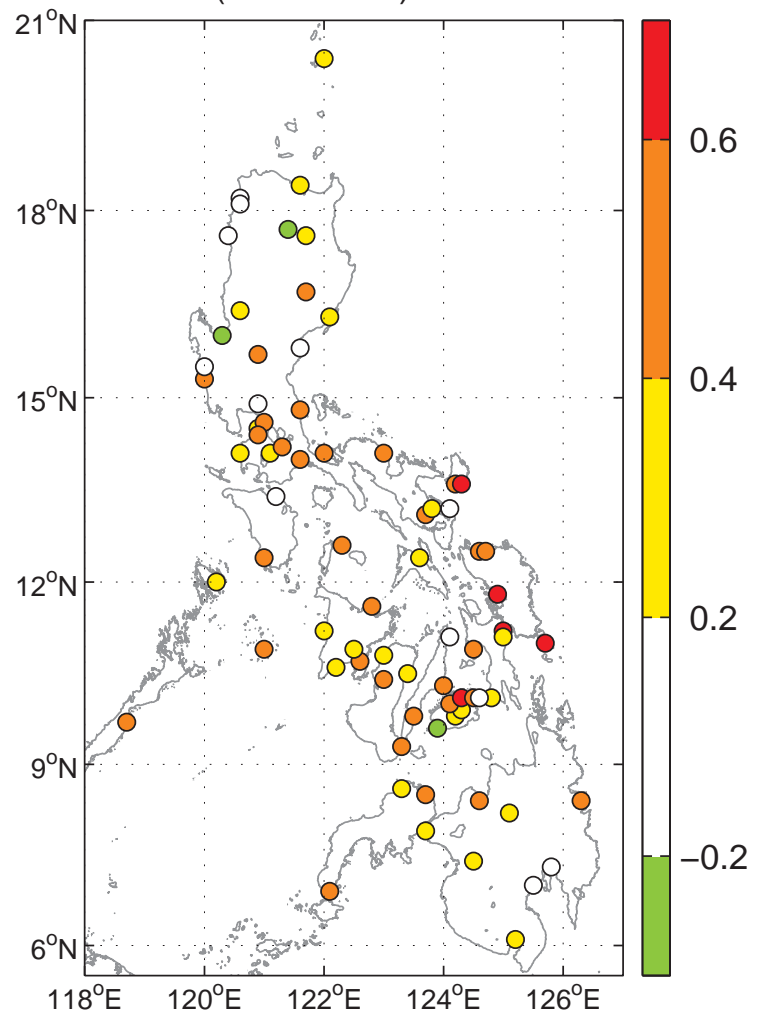

(c) Corr. hindcast (CFS) vs observed onset date

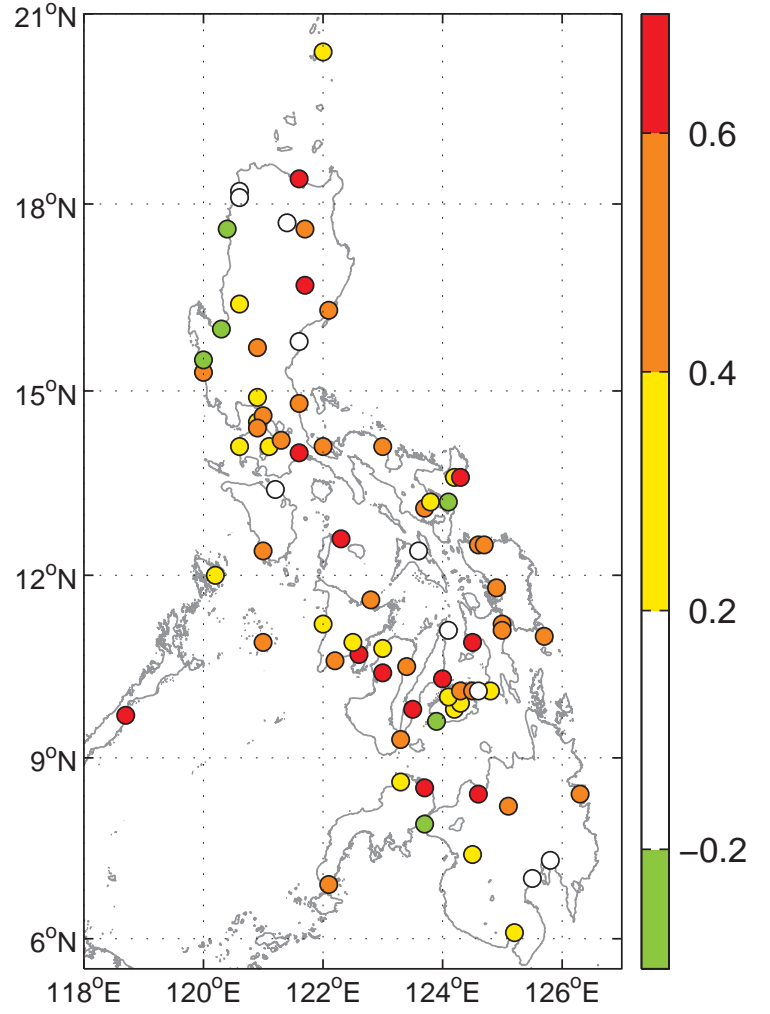

(b) Corr. hindcast (CA) vs observed onset date

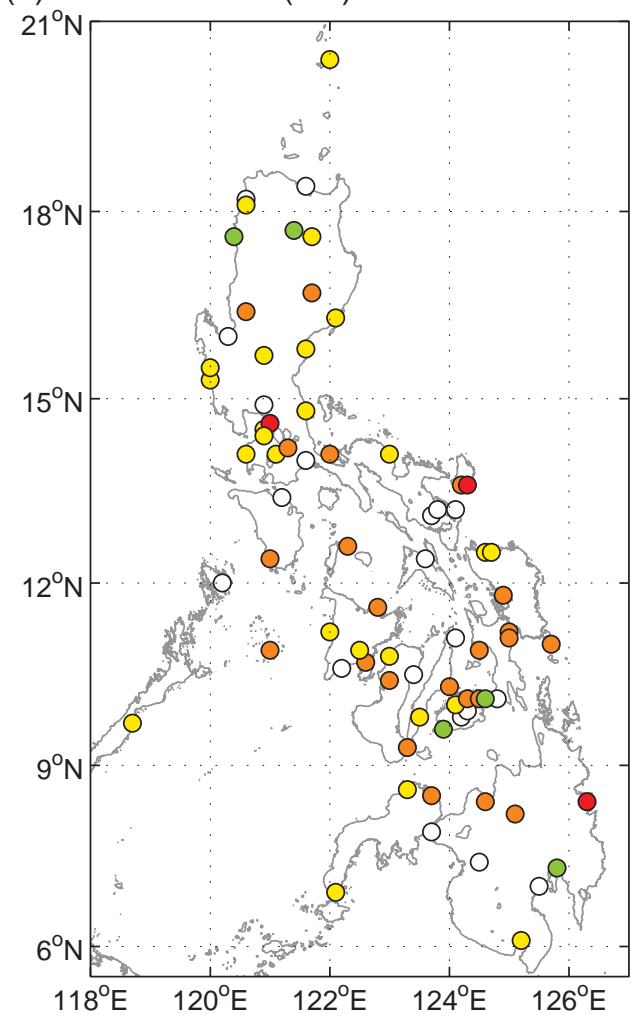

0.4

0.2

$-0.2$ (d) Corr. hindcast (MOM) vs observed onset date

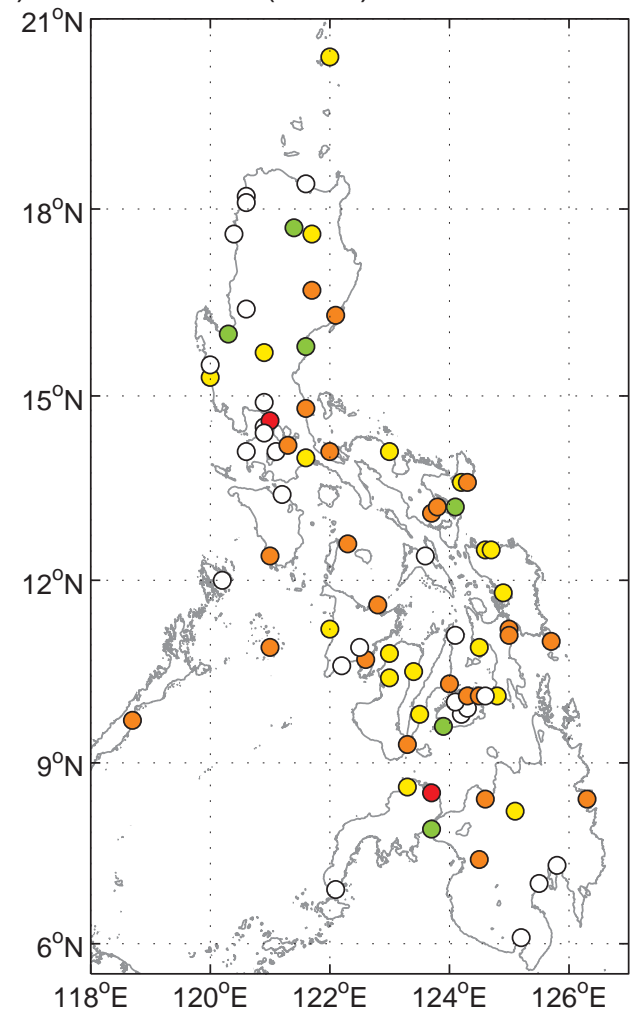

0.6

0.4

0.2 
(a) HSS hindcast (March SST) vs observed onset date

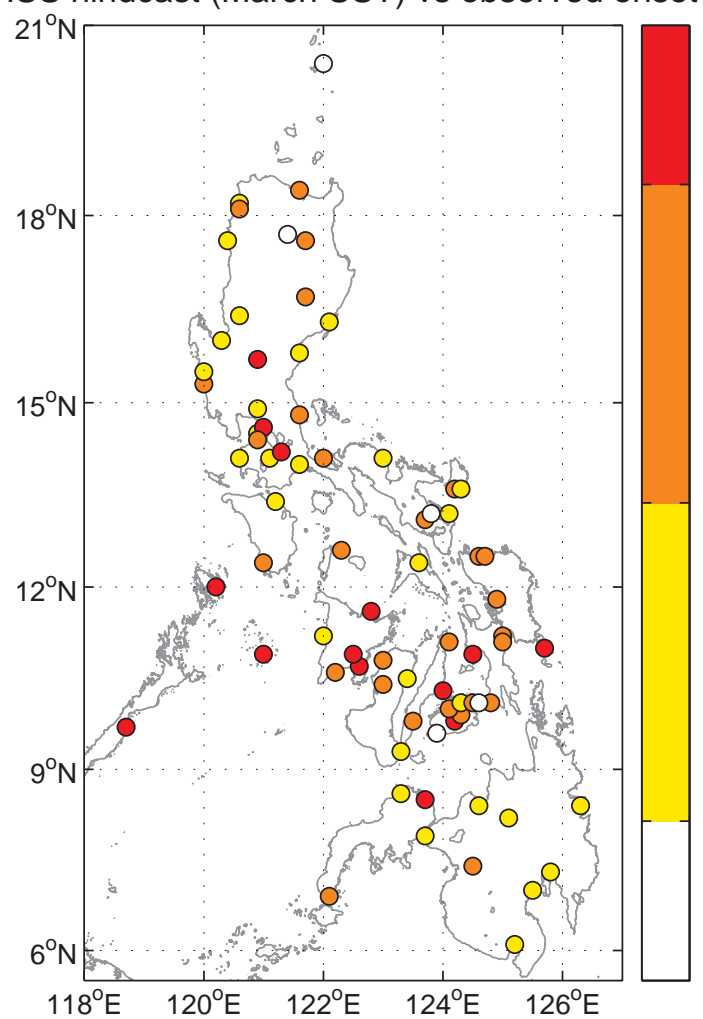

(b) HSS hindcast (CA) vs observed onset date

40

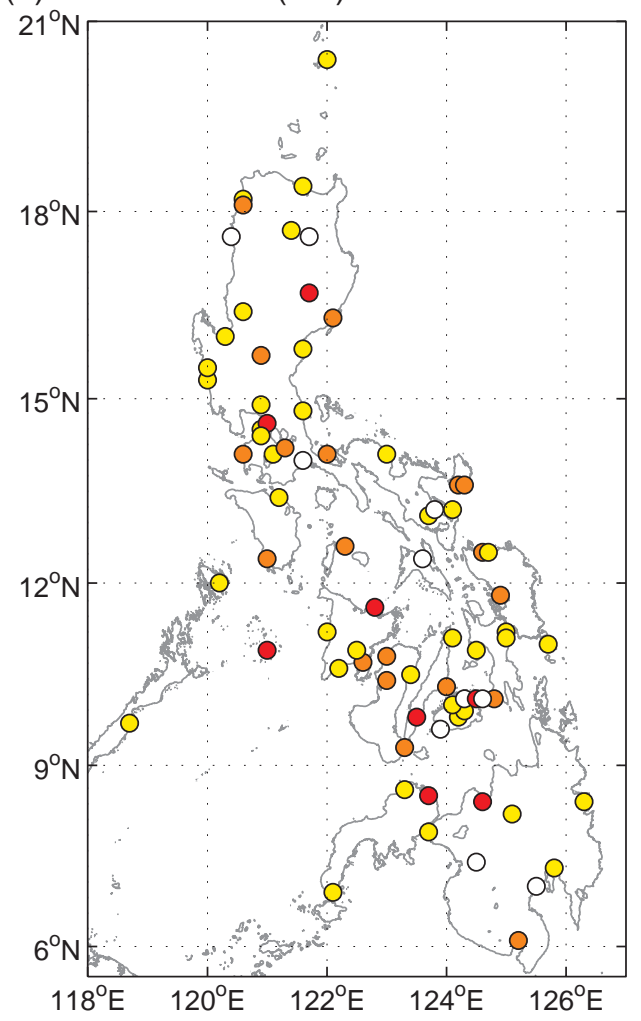

(d) HSS hindcast (MOM) vs observed onset date

(c) HSS hindcast (CFS) vs observed onset date
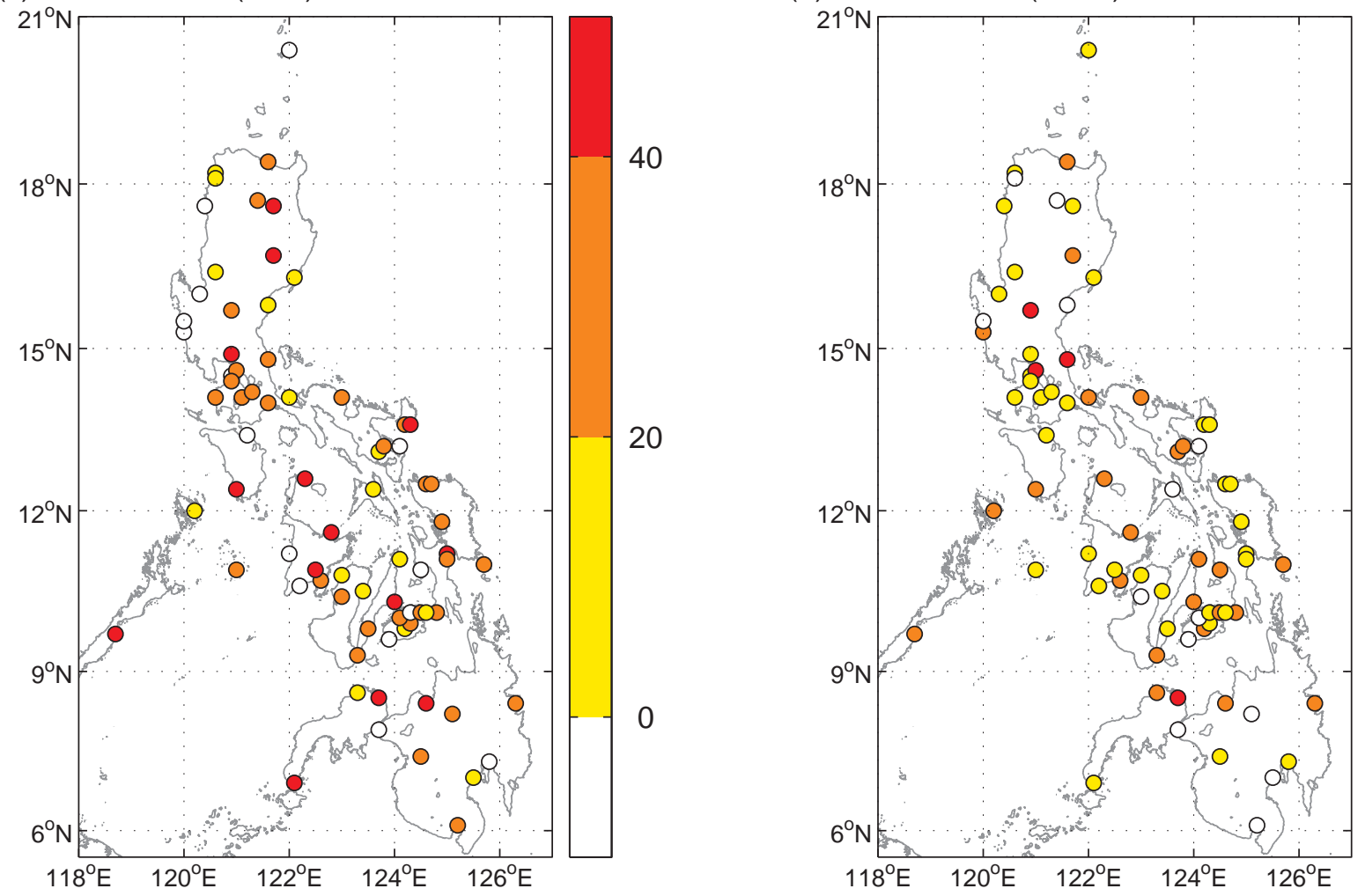

40 